\title{
The Influence of Alcohol Addiction on Cognitive Functions of the Representatives of Indigenous Population of Siberia
}

\author{
Nikolay Bokhan \\ Doctor of Medical Sciences, Professor, Corresponding Member of RAS, Honored Scientist of the RF, Director of Mental Health \\ Research Institute, Head of the Addictive Conditions Department, 4 Aleutskaya Str., Tomsk, Russia, 634014 \\ redo@mail.tomsknet.ru

\section{Anastasiya Peshkovskaya} \\ Junior Researcher of the Addictive Conditions Department, Mental Health Research Institute, \\ 4 Aleutskaya Str., Tomsk, Russia, 634014; peshkovskaya@sibmail.com
}

\begin{abstract}
Anna Mandel
Doctor of Medical Sciences, Professor, Leading Researcher of the Addictive Conditions Department Mental Health Research Institute, 4 Aleutskaya Str., Tomsk, Russia, 634014; anna-mandel@mail.ru

Irina Badyrgy

Chief physician, State budget-funded healthcare institution of the RT Republican drug abuse clinic 29/1 Kalinina Str., Kyzyl, Republic of Tyva; rndtuva@mail.ru

Ekaterina Mikhalickaya

Postgraduate student at the Mental Health Research Institute, 4 Aleutskaya Str., Tomsk, Russia, 634014 uzen63@mail.ru
\end{abstract}

\section{Doi:10.5901/mjss.2015.v6n6s5p337}

Abstract

\begin{abstract}
As a model for studying the ethnic and cultural aspects of alcohol abuse problem the narcological situation in the Republic of Tyva (Russia) which is relevant for Siberian region. Clinical and psychological examination of 155 alcohol addicted registered in the Republican drug abuse clinic (Kyzyl) was carried out, with 91 people of them being Tuvinian nationality, and 64 people Russians. In order to study the particularities of thinking and intellectual integrity of the alcohol abusers, the "Pictograms" technique was used. The content of the tested ones' memory was estimated using the "Learning 10 words" technique. The cognitive particularities of representatives of Tuvinian and Russian ethnos with alcohol addiction are described. The particularities of cognitive disorders of alcohol abusers have been determined that consist in reduced memory productivity, consistency of associative connections. The relation between graphic characteristics of drawings of the alcohol abusers which act as indicators of organic lesions of brain and the severity of clinical signs of alcoholic abuse is stated. In representatives of the Tuvinian ethnos, alcohol addiction damages the ability to speak in complex abstract terms and reduces the productivity of memorizing to a larger extent as compared to Russians, which confirms greater vulnerability of the indigenous ethnos to the effect of alcohol.
\end{abstract}

Keywords: alcohol addiction, cognitive disorders, thinking, memory, ethnic distinctions.

\section{Introduction}

The relevance of clinical and psychological studies of the problem of alcohol abuse is determined by the acute character of the narcological situation in the Eastern region of the Russian Federation and a high frequency of medical and social consequences of alcohol abuse (Koshkina, 2011; Bokhan et al., 2013; WHO, 2014). The history of Western industrial civilization spreading to the East and the consequences of acculturation stress in the indigenous population confirm the significant influence of ethnic and cultural factors on the context of formation of clinical and psychological particularities of 
mental and narcological disorders in various ethnic groups of population (Bisaliev et al., 2011; Epstein et al., 2000; Adrian, 2002; Alegria et al., 2008; Chartier and Caetano, 2010; Savchenko et al., 2015). The problem is especially vital in the ethnic groups whose acquaintance with strong drinks was provoked by representatives of other cultures.

The Republic of Tyva is an example of an area where the index of registered alcohol abuse incidence (1775 per 100 thousand people) exceeds the average for Russia (1566,3 per 100 thousand people) and demonstrates aggravation of problems related to consumption of alcohol. Among the population of the republic, the annual growth of alcohol consumption having negative consequences is observed. During the time span from 2010 (53,6 per 100 thous. people) to 2014 (106,17 per 100 thous. people), the index of alcohol consumption with negative consequences was characterized by annual growth, especially in 2013 and 2014; it amounted to $49,6 \%$ over the five years. In the republic, 3,2\% of population of employable age are registered in drug rehabilitation centers. The growth of incidence of "new wave" drug abuse disorders is registered, as well as that of alcohol abuse, the latter determining the structure of narcological situation in the region (Koshkina, 2011; Savchenko et al., 2015).

The Republic of Tyva is located in the central part of the Asian continent between the south of the East Siberia and the north of the Republic of Mongolia. The Tuvinians are continental Mongoloids, one of the indigenous peoples of the Sayan and Altai Uplands in the south of Siberia (the Upper Yenisei basin). The Republic of Tyva is the youngest state formation within the RF. The total population of the republic amounts to 312940 people (as of 2014), with the population density being 1,86 people $/ \mathrm{km}^{2}$. The specific weight of urban population is $51,22 \%$ (2014). The prevailing part of the republic's population is made up by representatives of the indigenous nation - Tuvinians (77\%), among them the Tuvinians-Tojins, one of the small-numbered peoples of the North. The share of Russians residing in the republic amounts to $20 \%$.

According to their origin, the Tuvinians belong to Altai language family and are in the Turkic language group. The Tuvinians' traditional confession is Buddhism, with elements of more ancient faiths preserved - shamanism. The main occupation of the Tuvinians has been cattle breeding since olden times. The majority of Tuvinians-Arats (this was the name of peasants in Tyva whose business was cattle breeding) led a nomadic life. They prepared milk vodka - araga from boiled sour milk. Araga was considered to be a sacred drink, and there was an ancient magical prohibition for women and children, as well as for men aged under 30 , to drink araga. Consumption of araga had sacral meaning - the drink was used in various magical rites.

Today, together with change brought about by modernization of the modern society, the representatives of traditional cultures - to which the Tuvinians also belong - have to change their value and motivation structure. The change of values structure in traditional societies is coupled with transformation of ethnic identity of their representatives, with its blurring, i.e. the increase of indefiniteness or marginality. Acculturation and acculturation stress act as conditions that, beyond doubt, promote the development of alcohol addiction (Epstein, Botvin \& Diaz, 2000; Alegria et al., 2008).

In the case of Tuvinian ethnos, the tradition of milk araga consumption settled over centuries has formed certain biochemical processes for processing the alcohol that are not the same as in Caucasoids, due to which the consequences of consuming an alien in the ethno-cultural attitude product (vodka) are accompanied by the progressive character of alcohol abuse.

Alongside with this, the research results give evidence about the essential influence of ethno-cultural factors on the clinical and dynamic characteristics of alcohol addiction (Udartseva et al., 2010). However, the studies of alcohol addiction development particularities in various population groups of Tyva are not numerous, and the clinical and psychological aspects of alcohol addiction in persons of Tuvinian and Russian nationality living in the republic are studied to even smaller extent.

The goal of the research is to find out the particularities of cognitive functions and the level of intellectual integrity under alcohol addiction in representatives of indigenous population of Siberia - people of Tuvinian nationality.

\section{Materials and Research Methods}

In 2013-2014, 155 alcohol addicts registered in the Republican drug abuse clinic of the Republic of Tyva (Kyzyl) were subjected to clinical and psychological examination, with 91 of them being Tuvinian nationals and 64 - Russians permanently residing within the Republic of Tyva. The latter were included into the comparison group.

In order to study the particularities of thinking and intellectual integrity of alcohol addicts, the "Pictograms" technique was used. As for studies having the ethno-cultural character, the method of pictograms is the most preferable because its basis - the pictographic image - is represented as a drawing being a universal means of communication, with the small weight of the verbal component in the method structure, which allows leveling out the difficulties of linguistic restrictions. 
The data on mnestic processes in alcohol addicts were supplemented with the results obtained using the "Learning 10 words" technique which allowed estimating the condition of the tested ones' memory.

The groups were compared using Mann-Whitney U-test. Correlation analysis was performed with Spearman r-test and Kendall T-tests.

\section{Research Results and Discussion}

The destructions of cognitive sphere caused by alcohol addiction are due to the effect of a number of factors: of clinical, biological, social and psychological nature. The impact of alcohol addiction on cognitive functions is evident. This is also about such consequences of alcohol addiction as cognitive activity disorders and formation of cognitive deficit (Goncalves et al., 2014; Naqvi \& Morgenstern, 2015). Alcohol abuse patients demonstrate intellectual and mnestic reductions that are the more expressed, the higher the gravity of the illness is (Bokhan et al., 2013).

It is operational characteristics of thinking that are pathologically changed first of all. Alongside with that, the cognitive sphere disorders accompanying the alcohol addiction have a various extent in different ethno-cultural conditions, in particular, for the Tuvinian and Russian ethnoses.

The focus of attention of this research has been memory and thinking - the characteristics and level of thought operations - in their interrelation to clinical and dynamic parameters of alcoholism.

Ethno-cultural particularities of intellectual integrity in alcohol addicts find their reflection in memory disorders, namely, in reduced productivity of mediating memorizing. The "10 words" technique aimed at studying the memory confirms mnestic disorders in Tuvinian and Russian alcohol addicts - their memory indices (the quantity of words in the third repetition and in repetition after an hour, presence of some words too many, getting stuck on them) is below the norms. With regard to this, in the Tuvinian group, the memorizing productivity index found with the main index of the technique - reproduction of words after an hour - being the index of direct memorizing (or actually the memory) is validly lower than in the group of Russians. In Tuvinians, this index makes on average 4,65+0,41 words, which is validly less $(p=0,017)$ than in the group of Russians where it equals $6,88+0,09$ on average (Table 1$)$.

Table 1. Distinctions in the direct words reproduction index in the Tuvinians and Russians after an hour $(p=0,017, " 10$ words" technique)

\begin{tabular}{|c|c|c|}
\hline \multirow{2}{*}{ The index of reproduction after an hour } & \multicolumn{2}{|c|}{ Absolute } \\
\cline { 2 - 3 } & $\mathrm{M} \pm \mathrm{m}$ & $\mathrm{Sd}$ \\
\hline Tuvinians & $4,65 \pm 0,4$ & 2,15 \\
\hline Russians & $6,88 \pm 0,7$ & 2,10 \\
\hline Norm & 9,0 & 1,0 \\
\hline
\end{tabular}

When studying the memory using the "Pictograms" technique, we have also obtained valid distinctions $(p=0,047)$ in the reproduction index characterizing the productivity of mediated memorizing. Its average values in the groups of Tuvinians and Russians are 6,74 and 8,94, respectively (Table 2).

Table 2. Distinctions in the mediated reproduction index in Tuvinians and Russians ( $p=0,047$, "Pictograms" technique)

\begin{tabular}{|c|c|c|}
\hline \multirow{2}{*}{ Mediated reproduction index } & \multicolumn{2}{|c|}{ Absolute } \\
\cline { 2 - 3 } & $\mathrm{M} \pm \mathrm{m}$ & $\mathrm{Sd}$ \\
\hline Tuvinians & $6,74+0,61$ & 3,18 \\
\hline Russians & $8,94+0,92$ & 2,76 \\
\hline Norm & $13,52+0,07$ & 1,42 \\
\hline
\end{tabular}

Both indices are below norm and are associated with cognitive reduction accompanying the alcohol addiction. Meanwhile, memorizing productivity reduction is pronounced to a validly smaller extent in Russians (Figure 1). 


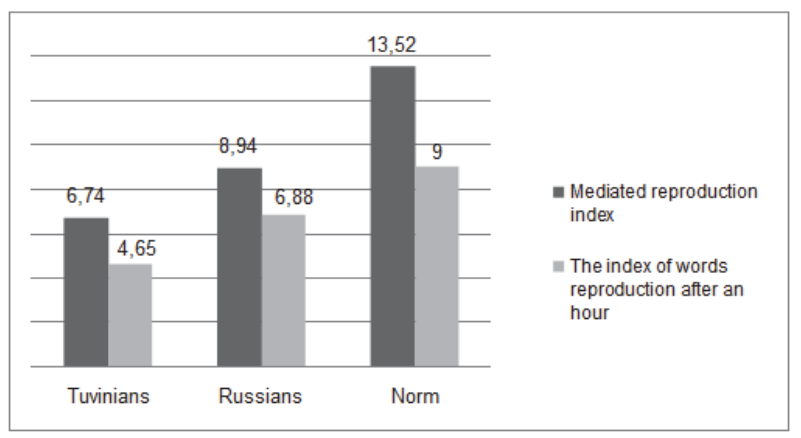

Figure 1. Summary data. Distinctions between the tested ones of the Tuvinian and Russian ethnicity in memory indices obtained by the pictograms technique $(p=0,047)$ and the " 10 words" one $(p=0,017)$

The following data illustrate the particularities of thinking in alcohol addicts of different ethnicity. The index of pictogram relevance characterizes the moderate abstractness, clarity and realism of thinking, as well as the ability to find an image close to the notion. The main feature of the intellectual operation required for performing the technique task consists in the word meaning being always wider than the image selected, on the one hand, and the drawing being also wider than the word meaning, on the other hand; they only coincide over a certain span, which is the shared meaning field of the notion and the drawing. It is the presence of such shared meaning field that acts the main sign of a reasonable choice.

The index of associations relevance determined using the "Pictograms" technique is validly higher in the group of Russians $(p=0,047)$. The Tuvinians are able to find an image relevant to the notion less than the Russians (the relevance indices are 9,85 and 11,78 , respectively) (Table 3 ).

Table 3. Distinctions between Tuvinians and Russians in the index of relevance $(p=0,047)$

\begin{tabular}{|c|c|c|c|c|}
\hline \multirow{2}{*}{ Images relevance index } & \multicolumn{2}{|c|}{ Absolute } & \multicolumn{2}{c|}{$\%$} \\
\cline { 2 - 5 } & $\mathrm{M} \pm \mathrm{m}$ & $\mathrm{Sd}$ & $\mathrm{M} \pm \mathrm{m}$ & $\mathrm{Sd}$ \\
\hline Tuvinians & $9,85+0,45$ & 2,35 & $65,67+3,0$ & 15,67 \\
\hline Russians & $11,73+0,44$ & 3,19 & $78,2+3,0$ & 21,27 \\
\hline Norm & - & - & $86,3+0,34$ & 6,81 \\
\hline
\end{tabular}

In each individual case, the index of pictographic images relevance reflects the respondent's ability to find logical correlation of the word semantics and the image, to "grasp" and capture the word semantics in the drawing. Otherwise, the respondent proves to be unable to avoid semantic "shifts", thought distortions in his attempts to get in the meaning field shared by the word and drawing. It is the complicated abstract notions of pictograms that are the most illustrative in what concerns the distortions, both in the group of Russians and in that of Tuvinians, such as "a bitter question", "justice", "development" etc.

So, the semantics of drawing is appropriate to the semantics of the "bitter question" notion in $61,9 \%$ of protocols of Tuvinian alcohol addicts and in $77,8 \%$ of protocols of the Russian ones where the meaning component "bitter" and "venom" is actualized (pictures of a bottle of poison, of a snake) and the component "question" (pictures in the shape of a question mark or the question mark itself) (Table 4). The shift of the notion meaning field in other protocols are reflected in capturing of the semantic emotional component "something unpleasant, offensive, insulting" in the drawing - pictures of one or two faces with a downward-sloping mouth, i.e. "a mean person", "one offended the other", of a man with a whip - "he wants to hit the other one, a bitter question is like this insult". The relevant images for the notion of "justice" include $29,6 \%$ of protocols of the Tuvinians and $44,4 \%$ of protocols of the Russians. The logical shifts actualize the emotional and evaluative component: "what is good" (the picture of the sun - "I like justice and I hate lies"; a man with arms up - "he is happy") as well as meaning attribution (a man with a briefcase is depicted - "this is an important officer, he must be just", a fist - "a man bangs the table with his fist - he defends his rightness, justice") (Table 4).

On balance, the proportion of the appropriate images per each complicated abstract notion in the protocols of Russians and Tuvinians and the standard quantity of images that are relevant to notions (Table 4) confirms the negative impact of alcohol addiction on the accessible generalization level. The impact consists in reduced accessible abstractions 
level, generalization distortions, and in actualization of irrelevant logical links.

Alongside with that, in Tuvininan nationals, alcohol abuse damages to a greater extent the capacity for generalization which is necessary and sufficient for a complicated abstract notion. As a result of alcohol addiction, generalization at the level of complicated abstract notions is accessible to Tuvinian alcohol addicts to a smaller extent as compared to the Russian ones of the same age and the same stage of the illness progress.

Table 4. The share of relevant images for individual notions of the pictograms technique in protocols of the tested ones

\begin{tabular}{|c|c|c|c|}
\hline \multirow{2}{*}{ Some notions of the pictograms technique } & \multicolumn{3}{|c|}{ The quantity of relevant images per notion, \% } \\
\cline { 2 - 3 } & Ethnicity of the tested ones & \multirow{2}{*}{ Standard quantity } \\
\cline { 2 - 3 } & Tuvinians & Russians & \\
\hline "bitter question" & 61,9 & 77,8 & - \\
\hline "justice" & 29,6 & 44,4 & 76 \\
\hline "development" & 66,7 & 88,9 & 78 \\
\hline "brave deed" & 66,7 & 77,8 & 86 \\
\hline "separation" & 63,0 & 66,7 & 89 \\
\hline
\end{tabular}

The index of thought operations relevance is influenced by actualization of images having an individual significance for the respondent. They are images having an emotional and personal "load", usually non-standard or frequent ones, so original to a certain extent. However, the abstraction level of these images is rather low and not associated directly with the semantic component of the notion. Abstraction does not go higher than the individual experience limits, and the associations are certain and directly related to realia of the examined one's life, which at the same time does not allow to classify the image as irrelevant because it is appropriate for the individual experience of the tested one and is mediated by the experience.

For example, in $11,1 \%$ of protocols of Tuvinians, the notion "bitter question" got pictures having an individual significance (a coin - "money is a bitter question"; the situation of getting fired; a bottle of spirit). The emotional and personal component of such images accentuates the feelings of the respondent, with the word which actualizes the image acting as a tool for projection. As for the cognitive sphere, the individually significant image, though not being strictly irrelevant, blocks the opportunity to exit to a higher abstraction level that the individual experience and certain life realia of the tested one.

The group of Tuvinians has a validly larger quantity of such images $(p=0,012)$ than in the group of Russians $-2,33$ and 1,0, respectively (Table 5).

Table 5. Distinctions according to the quantity of individually significant images in the drawings of the Tuvinians and Russians $(p=0,012)$

\begin{tabular}{|c|c|c|}
\hline \multirow{2}{*}{ Ethnicity of the tested ones } & \multicolumn{2}{|c|}{ Quantity of individually significant images } \\
\cline { 2 - 3 } & $\mathrm{M} \pm \mathrm{m}$ & $\mathrm{Sd}$ \\
\hline Tuvinians & $2,33+0,27$ & 1,41 \\
\hline Russians & $1,0+0,33$ & 1,0 \\
\hline Norm* & - & - \\
\hline
\end{tabular}

*there are no norm values for the quantity of individually significant images.

The index of commonality of associative links determined by the quantity of pictures reproducing in their content the typical, widespread, "banal" associations (e.g. when a heart pierced by an arrow is depicted for the notion "love") corresponds to the extent of conformity of thinking.

In drawings by the Tuvinians and Russians, the particularities of associative links were found for a number of notions. So, "a happy festival" which has got standard "generic cultural" pictures of flags, balloons, New Year tree (from the class of repeated images) in both groups was represented in 7,4\% of Tuvininans' pictograms by the pictures of "a competition of fighters", "races and fighters", because "there are competitions during the festival". For the notion of "a tasty supper", 25,9\% of Tuvinians depict various dishes of the national cuisine - "Tuvinian soup", "khan", and the notion of "wealth" had pictures of "a flock of sheep", "a yurt, a horse, a cow", "a lot of cattle" in 18,5\% of pictograms of the Tuvinian group. All in all, the particularities revealed of the standard character of associative links touch on the presence 
of traditional national topics range in the Tuvinians' pictogram images, as standard for the Tuvinian culture as the Russians' pictogram images are standard for the Russian (or all-Russian) culture. Thus, in Tuvinians, alongside with the generally accepted thought patterns, there are associative elements which are specific exclusively for the culture of the Tuvinian people. In other words, the thinking of both Tuvinans and Russians to an equal extent relies on the widespread, standard associative patterns, yet in the Tuvinian ethnos the standard associative links are culturally specific.

The values of commonality index in the groups of Tuvinian and Russian alcohol addicts do not go beyond the norm range. The associations reproduce the generally accepted "patterns" with the moderate frequency; there are no original creative solutions in the drawings of the alcohol addicts (Table 6).

Table 6. Commonality index values for the drawings of alcohol addicts

\begin{tabular}{|c|c|c|}
\hline \multirow{2}{*}{ Drawings commonality index } & \multicolumn{2}{|c|}{ Absolute } \\
\cline { 2 - 3 } & $\mathrm{M} \pm \mathrm{m}$ & $\mathrm{Sd}$ \\
\hline Tuvinians & $3,74+0,23$ & 1,2 \\
\hline Russians & $5,11+0,56$ & 1,69 \\
\hline Norm & $4,34+0,06$ & 1,22 \\
\hline
\end{tabular}

While influencing the intellectual integrity of the respondents, the alcohol addiction also demonstrates the relation to fine features of performing the pictograms technique. In particular, the gravity of clinical symptoms is related to structural and graphic particularities of the drawing. It has been stated that the phenomenon of graphic stereotypy (repeating of human figures or small human body details, objects, symbols in the drawings) has a connection with the duration of withdrawal syndrome in the group of Tuvinians. The use of the previous drawing for constructing an image for the following notion of the pictogram - the "united system" phenomenon - correlates with the quantity of treatment attempts made in the group of Russians and the duration of withdrawal syndrome in Tuvinians (Table 7). In its turn, the longer the duration of systematic alcohol consumption is, the more frequent perseveration - direct repetition of identical pictures for two and more notions of the pictogram - is (Table 7).

Table 7. Correlation links of clinical and dynamical parameters of alcohol addiction and graphic particularities of drawings in the groups of Tuvinian (marked dark) and Russian (marked fair) alcohol addicts

\begin{tabular}{|c|c|c|c|}
\hline \multirow[b]{2}{*}{$\begin{array}{l}\text { Particularities of doing the pictograms } \\
\text { technique tests }\end{array}$} & \multicolumn{3}{|c|}{ Clinical and dynamical parameters of alcohol addiction } \\
\hline & $\begin{array}{c}\text { Withdrawal syndrome } \\
\text { duration }\end{array}$ & $\begin{array}{c}\text { Quantity of attempts of } \\
\text { treatment }\end{array}$ & $\begin{array}{c}\text { Duration of systematic alcohol } \\
\text { consumption }\end{array}$ \\
\hline \multicolumn{4}{|c|}{ Graphic phenomena - indicators of organic disorders } \\
\hline The united system phenomenon & $\begin{array}{c}\mathrm{T}=0,30 \\
\mathrm{p}=0,029\end{array}$ & $\begin{array}{c}T=0,68 \\
p=0,032\end{array}$ & \\
\hline Stereotypy & $\begin{array}{c}r=0,41 \\
p=0,035\end{array}$ & & \\
\hline Perseveration & & $\begin{array}{c}r=0,42 \\
p=0,038\end{array}$ & \\
\hline \multicolumn{4}{|c|}{ Phenomena - indicators of thinking disorders } \\
\hline Inappropriate graphic symbols & & & $\begin{array}{c}r=0,42 \\
p=0,043\end{array}$ \\
\hline \multicolumn{4}{|l|}{ Intellectual characteristics of drawings } \\
\hline Associative links originality & $\begin{array}{l}r=-0,69 \\
p=0,040\end{array}$ & & \\
\hline Schematic character & $\begin{array}{l}T=-0,63 \\
p=0,018\end{array}$ & & \\
\hline
\end{tabular}

The above graphic features of the alcohol addicts' drawings - stereotypy, united system phenomenon, perseveration reflect the disorders having an organic nature.

Alongside with that, as the gravity of alcohol addiction manifestation increases, the inappropriate graphic symbols are registered more frequently (e.g. an exclamation mark for the notion of "justice"). A more prolonged withdrawal syndrome is accompanied by reduced originality of associations and by schematic character of drawings in alcohol addicts. 


\section{Conclusion}

Thus, the cognitive particularities of both Tuvinian and Russian alcohol addicts, regardless of their national affiliation, are characterized by reduced productivity of memorizing, reduced share of appropriate images for abstract notions of the "Pictograms" technique, which gives evidence about the negative impact of alcohol addiction on the accessible generalization level consisting in reduced accessible abstractions level, distortions of generalization, and actualization of irrelevant logical relations.

Meanwhile, in representatives of the Tuvinian ethnos, alcohol addiction damages to a greater extent the ability to operate complex abstract notions $(p=0,047)$. Reduced productivity of memorizing is also more pronounced in the Tuvinian alcohol addicts as compared to the Russian ones $(p=0,017)$, which confirms greater vulnerability of the indigenous ethnos to the effect of alcohol.

Individually significant pictogram images that carry an emotional and personal "load" and so are limited by a certain situation within the individual experience and realia of the tested one's life prevail among the Tuvinian alcohol addicts $(p=0,012)$ as compared to the Russian ones.

The thinking of both Tuvinians and Russians addicted to alcohol is characterized by relying on standard, generally accepted "patterns". No original creative solutions are expressed in the drawings of alcohol addicts.

The particularities revealed also give evidence about the Tuvinians having associative elements which are actually specific for the culture of the Tuvinian people alongside with the generally accepted thought patterns of associative elements. In other words, thinking of both Tuvinians and Russians similarly relies on standard associative patterns yet in the Tuvinians, the standard associative links are specific to culture.

The structural graphic particularities of the drawings are due to the gravity of clinical signs of alcohol addiction in patients of the Russian and Tuvinian nationalities. The duration of systematic alcohol consumption, withdrawal syndrome, the quantity of treatment attempts made are related to the phenomena which are indicative of the organic disorders of the brain - perseveration, stereotypy, a "united system".

Diagnostics of cognitive sphere disorders in alcohol addicts serves to objectives of therapy, the performance of which in relation to patients belonging to other cultures necessitates taking into account the ethnic and cultural features of clinical and psychological interrelations in cases of alcohol addiction.

\section{Acknowledgements}

The work was performed with the support of RHSF grant No. 14-06-00531a "Mental and social, ethnic and cultural, genetic determinants of alcohol addiction in representatives of the indigenous population of Siberia".

\section{References}

Adrian, M. (2002). A critical perspective on cross-cultural contexts for addiction and multiculturalism: Their meanings and implications in the substance use field. Substance Use \& Misuse, 37(8-10), 853-900.

Alegria, M., Canino, G., Shrout, P. E., Woo, M., Duan, N., Vila, D., Torres, M., Chen, C.N., \& Meng, X.L. (2008) Prevalence of mental illness in immigrant and non-immigrant U.S. Latino groups. American Journal of Psychiatry, 165, 359-369.

Bisaliev, R.V., Krechina, E.V., Khaninev, N.F. (2011). Etnokulturalnie aspekty alkogolnoi zavisimosti [Ethno-cultural aspects of alcohol addiction]. Nevrologhicheskiy vestnik, XLIII, 1, 68-75.

Bokhan, N.A., Mandel', A.I., Peshkovskaya, A.G., Badyrghy, I.O., Aslanbekova, N.V. (2013). Etnoterritorial'naya gheteroghennost' formirovaniya alkogol'noi zavisimosti u korennogo naseleniya Sibiri [Ethno-territorial heterogeneity of formation of alcohol addiction in indigenous population of Siberia]. Zhurnal nevrologhii i psikhiatrii im. S.S. Korsakova, 6, 9-14.

Chartier K., Caetano R. (2010). Ethnicity and Health Disparities in Alcohol Research. Alcohol Research \& Health, 33, 1, 2, $152-160$.

Epstein, J.A., Botvin G.J., Diaz T. (2000). Alcohol use among Hispanic adolescents: Role of linguistic acculturation and gender. Journal of Alcohol and Drug Education, 45(3), 18-32.

Goncalves, P.D., Ometto, M., Sendoya, G., Lacet, C., Monteiro, L., Cunha, P.J. (2014). Neuropsychological Rehabilitation of Executive Functions: Challenges and Perspectives. Journal of Behavioral and Brain Science, 4, 27-32.

Koshkina, E.A. (2011) Zabolevaemost' psikhicheskimi i povedencheskimi rasstroistvami svyazannymi s upotrebleniem psikhoaktivnykh veshchestv $v$ Rossiyskoi Federatsii v dinamike za 5 let [Incidence of mental and behavior disorders related to use of psychoactive substances in the Russian Federation in 5-year dynamics]. Voprosy narkologhii, 1, 17-27.

Naqvi, N.H., Morgenstern, J. (2015). Cognitive Neuroscience Approaches to Understanding Behavior Change in Alcohol Use Disorder Treatments. Alcohol Res., 37(1), 29-38.

Savchenko, M., Bokhan, N., Plotnikov, E. (2015) Analysis of alcohol dependence in indigenous peoples in Northern Siberia. Archives of Psychiatry and Psychotherapy, 3, 14-20. 
Udartseva, T.L., Badyrghy, I.O., Mongush, Ch.K. (2010) Psikhologhicheskie factory alkogol'nogo potrebleniya u tuvintsev [Psychological factors of alcohol consumption in Tuvinians]. Mir nauki, kultury, obrazovaniya, 1(20), 234-236.

WHO (2014). Global status report on alcohol and health. Geneva: World Health Organization. 